\title{
The Paris Agreement and next steps in limiting global warming
}

\author{
Steven K. Rose ${ }^{1} \cdot$ Richard Richels $^{1}$ • \\ Geoffrey Blanford $^{1}$ - Thomas Rutherford ${ }^{2}$
}

Received: 7 March 2016 / Accepted: 26 February 2017 / Published online: 25 March 2017

(C) The Author(s) 2017. This article is published with open access at Springerlink.com

\begin{abstract}
The Paris Climate Agreement sets out an aggressive goal of limiting global average warming to well below $2{ }^{\circ} \mathrm{C}$. As a first step, virtually all countries have put forth greenhouse gas emission reduction pledges in the form of nationally determined contributions, or NDCs, for the 2030 timeframe. Our analysis looks beyond the NDCs to explore potential post-2030 regional emissions reduction participation and ambition. For each scenario, we examine the implications for global emissions and long-term temperature. We then evaluate the regional consequences for energy systems and ensuing costs. We conclude by reflecting on the additional global abatement costs of tightening temperature goals. Overall, this study provides a multidimensional characterization of the scale of regional effort supporting climate outcomes, details important to decision-makers as they consider mid-century emissions targets, and longrun climate objectives.
\end{abstract}

An earlier version of this paper was presented at the Twenty-First Meeting of the Conference of the Parties (COP21) in Paris, France. We have benefitted substantially from discussions with Henry Jacoby, Michael Oppenheimer, David Victor, and Jonathan Wiener. We have also received many constructive comments from three anonymous referees. All remaining errors and misperceptions remain with the authors. The views presented here are solely those of the authors and do not represent those of the Electric Power Research Institute (EPRI) or funding entities.

Electronic supplementary material The online version of this article (doi:10.1007/s10584-017-1935-y) contains supplementary material, which is available to authorized users.

Steven K. Rose

srose@epri.com

1 Energy and Environmental Analysis Research Group, Electric Power Research Institute, Washington, DC and Palo Alto, CA, USA

2 Department of Agricultural and Applied Economics, University of Wisconsin-Madison, Madison, WI, USA 


\section{Introduction}

The Paris Agreement on Climate Change calls for limiting the rise in global mean temperature to "well below" $2{ }^{\circ} \mathrm{C}$ and identifies $1.5^{\circ} \mathrm{C}$ as a warming limit worth pursuing (COP 2015). While scientists and policymakers will continue to debate the appropriate measure and whether the goal is even achievable, the agreement clearly reflects the intention of world leaders "to prevent dangerous anthropogenic interference with the climate system."1

In the near-term, the Paris Agreement consists of emissions reduction pledges-nationally determined contributions or NDCs-by nearly all the world's countries for the 2030 timeframe. Participation in the agreement is broad, with countries offering pledges representing almost all of the world's current anthropogenic greenhouse gas (GHG) emissions. However, the pledges of many lower-income countries are conditional on international financial and technical assistance. Countries with conditional pledges or no pledges account for roughly $30 \%$ of global emissions but over 50\% of the current global population, and their share of both global emissions and population is likely to increase in the future.

A number of analyses have evaluated the implications of the NDCs for emissions (e.g., Jacoby and Chen 2014; Reilly et al. 2015; UNEP 2015; Fawcett et al. 2015; Iyer et al. 2015; Rogelj et al. 2016). Using different approaches, these analyses have explored the relationship between the current round of NDCs and the long-term temperature goals of the Paris Agreement. Their focus has been on global emissions: the aggregate implications of the NDCs followed by top-down specifications of future global pathways designed to be consistent with the long-run temperature goal. Broadly, these studies have concluded that while the 2030 pledges do not in themselves determine whether the long-run goal can be met, significantly greater ambition post-2030 is required to reach the goal. These findings have put the aspirations expressed in the NDCs in perspective and provided valuable information regarding future global effort for subsequent negotiations.

In this study, we take a different approach to characterizing potential post-2030 action, beyond the NDCs. Rather than constructing a global emissions path perforce consistent with the long-run goal, we design scenarios to explore varying degrees of participation and ambition on a regional basis. This is a new and instructive exercise because it links potential scenarios for the evolution of commitments beyond NDC pledges by individual countries and regions to longrun temperature pathways: pathways that may or may not achieve the Paris Agreement's goal. We also, for comparison, explore a top-down scenario in which the world follows regional emissions paths like the NDCs to 2030 and then collaboratively pursues a least-cost pathway to limiting global temperature to $2{ }^{\circ} \mathrm{C}$. This design is similar to that used by Kriegler et al. (2015) to explore the implications of delayed effort, but has not been previously examined in the context of the Paris Agreement. This scenario, which entails extremely rapid (and costly) reductions between 2030 and 2050, provides a compelling characterization of the tenuous compatibility of the NDCs with the $2{ }^{\circ} \mathrm{C}$ goal. When this scenario is compared with the regional bottom-up policy scenarios, we are able to offer a well-defined picture of the level, timing, and distribution of effort that may be required to achieve the Paris Agreement objective.

In addition to a novel scenario design for exploring abatement beyond the NDCs, our analysis also provides important details on the underlying transformation of the energy system and attendant economic costs, again at a regional level. Using an integrated framework, we examine the regional, technological, and economical implications of post-NDC abatement

${ }^{1}$ Article 2 of the UN Framework Convention on Climate Change (UNFCCC 1994). 
pathways. Our results provide a coherent and consistent view of the nature of the regional challenges associated with alternative levels of effort. Finally, we reflect on the welfare implications and compare the rising welfare costs of additional abatement effort from alternative perspectives to the potential value in terms of avoided temperature change. Together, our results constitute essential details that are important to decision-makers as they consider midcentury targets and long-run objectives. ${ }^{2}$ In the next section, we describe the model scenarios in detail, then present modeling results for global emissions, global temperature, regional energy mix, and economic costs. The final section contains our concluding comments.

\section{The scenarios}

Table 1 describes the structure of the main analysis. We first develop the set of bottom-up regional emissions policy scenarios and then consider the top-down scenario that has a $2{ }^{\circ} \mathrm{C}$ climate objective. For each region, the bottom-up scenarios have been constructed to explore a broad range of post-2030 regional emissions futures. This allows for a systematic examination of increasing levels and combinations of post-2030 regional emissions reduction ambition. We begin with scenarios that explore increasingly tighter emissions constraints on the major emitters of the world, followed by scenarios that add in progressively more ambitious constraints on developing country emissions. The scenario sequencing is not a prediction about how policy might unfold, but designed to separate the effects of regional ambition and participation, with Table 1 representing our core scenarios. ${ }^{3}$

Contingency statements in the NDCs of developing countries call for international financial and/or technological assistance. In the event that such international support does not materialize at the levels requested, they have said that they will either reduce their commitment or withdraw them altogether. Hence, we explore a wide range of emission reductions reflecting this uncertainty. However, instead of modeling developing country NDCs with and without contingencies, we examine alternatives for when emissions might peak and how they might decline in this part of the world, including not at all.

For our analysis, we divide the globe into six regions: the USA, the EU, China, India, the remaining countries comprising the group of 20 (OG20), and the rest of world denoted as other countries (OC). Our first scenario is the baseline. This represents a no-policy scenario from which emission reduction effort is measured. Scenarios 2, 3, and 4 examine increasingly more stringent emissions constraints on the four regions which currently comprise the major emitters, that is, the USA, the EU, the OG20 countries, and China. These regions will henceforth be referred to as the major emitters. We assume that each will be successful in implementing their NDCs. For the USA, this means that economy-wide GHGs are reduced by $28 \%$ below their 2005 levels by 2025, and for the EU, emissions are reduced by $40 \%$ below 1990 levels by 2030, while OG20 reductions are an aggregation of the NDC emission reduction pledges from each of the countries in the region (see SM Section 1b). Lastly, China's $\mathrm{CO}_{2}$ emissions peak by 2030 with its $\mathrm{CO}_{2}$ intensity of output falling $60 \%$ below 2005 levels by 2030 .

\footnotetext{
2 The Paris Agreement adoption text calls for countries, by 2020, to communicate their mid-century, low GHG development strategies in accordance with Article 4 paragraph 19 of COP (2015).

${ }^{3}$ In addition to the scenarios in Table 1, we have explored other combinations of regional participation and ambition to more fully flesh out potential future emissions and climate. Supplementary Material (SM) Table SM3 provides a matrix of the fuller set of regional policy scenarios, and the SM provides results.
} 


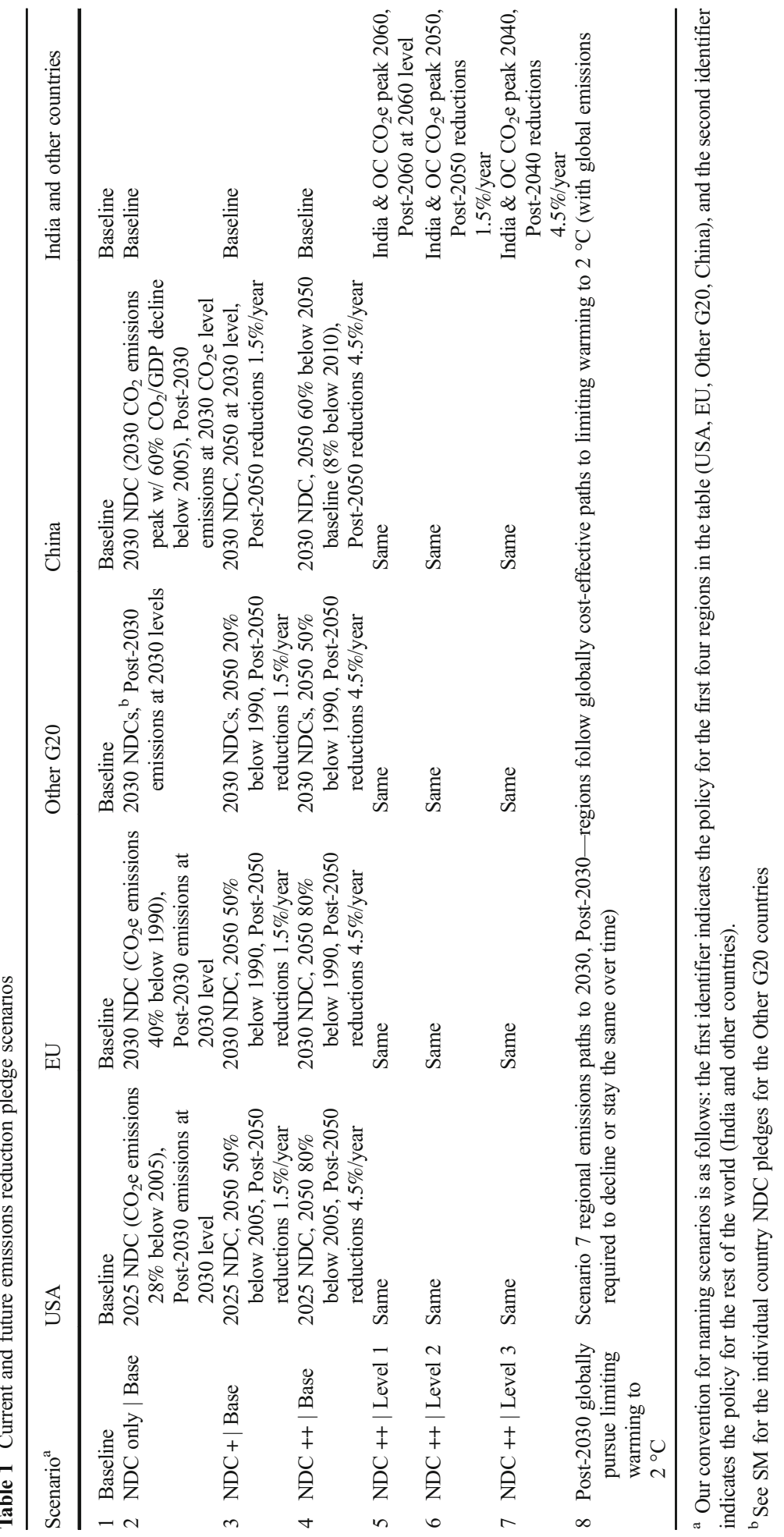


In scenario 2 ("NDC only"), the major emitters implement their NDCs but do not tighten their pledges in the future, i.e., emissions remain capped at 2030 levels. While this is counter to the intent of the Paris Agreement that indicates that parties should increase their level of ambition in the future, scenario 2 provides a useful benchmark for measuring additional post2030 effort.

Scenarios 3 and 4 ("NDC +" and "NDC ++") assume that future negotiations result in even tighter constraints on post-2030 major emitter emissions. Specifically, we suppose that the USA and EU pursue additional ambition of 50 or $80 \%$ reductions in emissions by 2050 relative to their respective base years. The latter set of targets is consistent with public statements by the two regions, including within their NDC submissions. ${ }^{4}$ The former set of $50 \%$ targets represents less ambitious objectives or partial success towards reaching the more ambitious $80 \%$ goals. For the OG20 countries, we assume targets of 20 and 50\% below 1990 levels by 2050 for scenarios 3 and 4, respectively. The alternative 2050 targets are designed to reflect the fact that many OG20 country NDCs represent substantial reductions and several higher income members have suggested greater ambitions for the future, but there is still uncertainty regarding the actions of countries contained in this group and baseline growth that is likely stronger for the emerging economies in OG20. Finally, for China post-2030, we consider mid-century targets that represent varying degrees of peak and decline and broader GHG coverage. Specifically, in scenario 3, a gradual peak and decline policy constrains 2050 emissions to 2030 levels before declining, while in scenario 4, a rapid peak and decline policy constrains 2050 emissions to $60 \%$ below 2050 baseline levels ( $8 \%$ below 2010). For both scenarios, we also broaden the China emissions constraint from a $\mathrm{CO}_{2}$ only policy to $\mathrm{CO}_{2}$ equivalent $\left(\mathrm{CO}_{2} \mathrm{e}\right)$ constraints that include all GHGs covered under the Kyoto Protocol $\left(\mathrm{CO}_{2}\right.$, methane, nitrous oxide, and fluorinated gases). Scenarios 2, 3, and 4 also exhibit increasingly more ambitious constraints post-2050, with emissions in the major emitters declining by $0,1.5$, or $4.5 \%$ per year, respectively. ${ }^{5}$

For scenarios 5 through 7, we add emissions constraints for India and OC to the most ambitious policies for the major emitters. While scenarios 2 through 4 assume that India and OC do not pursue new climate policies, ${ }^{6}$ scenarios 5 through 7 represent uncertainty about the degree to which the regions will be able to pursue emissions constraints. Specifically, scenarios 5 through 7 consider increasingly more ambitious emissions peaking pathways, with post2050 leveling off ("Level 1"), mid-century peak and decline ("Level 2"), and before midcentury peak and stronger decline ("Level 3 "). Emissions are unconstrained until the peak year and then emissions decline at $0,1.5$, or $4.5 \%$ per year, respectively. Scenarios 5 through 7 depict increasing levels of ambition analogous to scenarios 2 through 4 for the other regions.

Our final scenario, scenario 8, represents our single "top-down" scenario. It is designed to identify the global and regional emissions paths for holding global mean temperature rise at or below $2{ }^{\circ} \mathrm{C}$ relative to preindustrial levels, with additional effort towards the goal beginning post-2030. Specifically, all regions follow scenario 7 levels of effort through 2030 (NDC ++ or Level 3), followed by globally coordinated regional effort post-2030 for limiting warming to below $2{ }^{\circ} \mathrm{C}$, where regional post-2030 effort is allocated on a least-cost basis. Comparing results from our previous scenarios to scenario 8 provides insights regarding the levels of effort

\footnotetext{
$\overline{4_{\text {www4 }} \text {.unfecc.int/Submissions/INDC. }}$

${ }^{5}$ Note that our post-2050 regional policy specification does not produce negative $\mathrm{CO}_{2} \mathrm{e}$ emissions caps. However, some scenarios do produce results with negative regional $\mathrm{CO}_{2}$ emissions (Section 3).

${ }^{6}$ In the case of India, a key part of its NDC pledge is to reduce the emissions intensity of GDP by 33 to $35 \%$ by 2030 from 2005 levels. Our assumptions suggest that India could achieve this goal in the baseline scenario.
} 
within and across regions in terms of the adequacy of the regional bottom-up policies and the stringency necessary for avoiding $2{ }^{\circ} \mathrm{C}$ of warming or less.

Note that, in our scenarios, we do not explicitly model proposed sector-specific policies or regulations (e.g., non-fossil requirements, efficiency standards). Given our focus on post-2030 emissions pathways, we have decided not to make assumptions about this level of policy detail over time but instead allow the model to identify the cost-effective economy-wide strategies for emissions-constrained futures. We also note that, in our regional policy scenarios (scenarios 2 through 7), regions are constrained to (a) using abatement within their region, and (b) not having temporal flexibility (i.e., emission allowance banking and borrowing). Finally, within this restricted regional abatement context, we allow regions to relax their annual emissions caps at a price of $\$ 1000 / \mathrm{tCO}_{2} \mathrm{e}$. This mechanism provides us with novel perspective on the relationship between policy stringency and abatement options (see SM Section $1 \mathrm{f}$ for further details). ${ }^{7}$

\section{The impact on regional and global emissions}

We use MERGE (a model for evaluating regional and global effects of greenhouse gas reduction policies) for this analysis. MERGE is an inter-temporal equilibrium model which captures the long-run interdependence of global economic, energy, and climate systems. MERGE is solved through a dynamic optimization of weighted regional utility of consumption over time subject to constraints-emissions or temperature in this study. ${ }^{8}$

Figure 1 shows the regional baselines together with the resulting emissions in each scenario. ${ }^{9}$ First and foremost, we find that all the levels of abatement effort are non-trivial, even by 2050. Simply maintaining post-2030 emissions at NDC or peaking levels respectively is a notable departure from baselines in all regions. Going significantly further, the most ambitious regional policies-NDC ++ and Level 3-imply rapid reductions through midcentury and near-zero emissions by 2100 in all regions. The $2{ }^{\circ} \mathrm{C}$ post- 2030 pathway is even more ambitious, calling for negative or zero $\mathrm{CO}_{2} \mathrm{e}$ emissions by mid-century in most regions. Note that both scenarios 7 and 8 result in negative energy system $\mathrm{CO}_{2}$ emissions for all regions in this century (Figure SM3). In all policy scenarios, the deviations from baseline are particularly significant for transitional and developing economies, where the greatest emissions growth would be expected without climate policy.

In Fig. 2a, we see that reductions by the major emitters alone can be consequential for global emissions, but insufficient for permanently reversing the positive rate of growth. Reversing the rate of growth calls for more than NDC effort and much broader participation. This is true even for scenario 4, our most ambitious long-run major emitters' strategy. Acting alone, the current major emitters could change the direction of the rate of growth in global emissions but the reversal would only be temporary.

It is not until the rest of the world constrains emissions that global emissions permanently peak (scenarios 5, 6, and 7). Our results indicate that, for global emissions to peak and decline this century, a peaking of developing country emissions is likely required, combined with significant effort in developed and transitional countries.

\footnotetext{
7 This type of mechanism has been referred to as a "safety valve." See Pizer (1997) for background.

${ }^{8}$ See SM Section 1 for additional modeling details.

${ }^{9}$ A description of the dynamics underlying the baseline scenario is provided in SM Section 1a.
} 


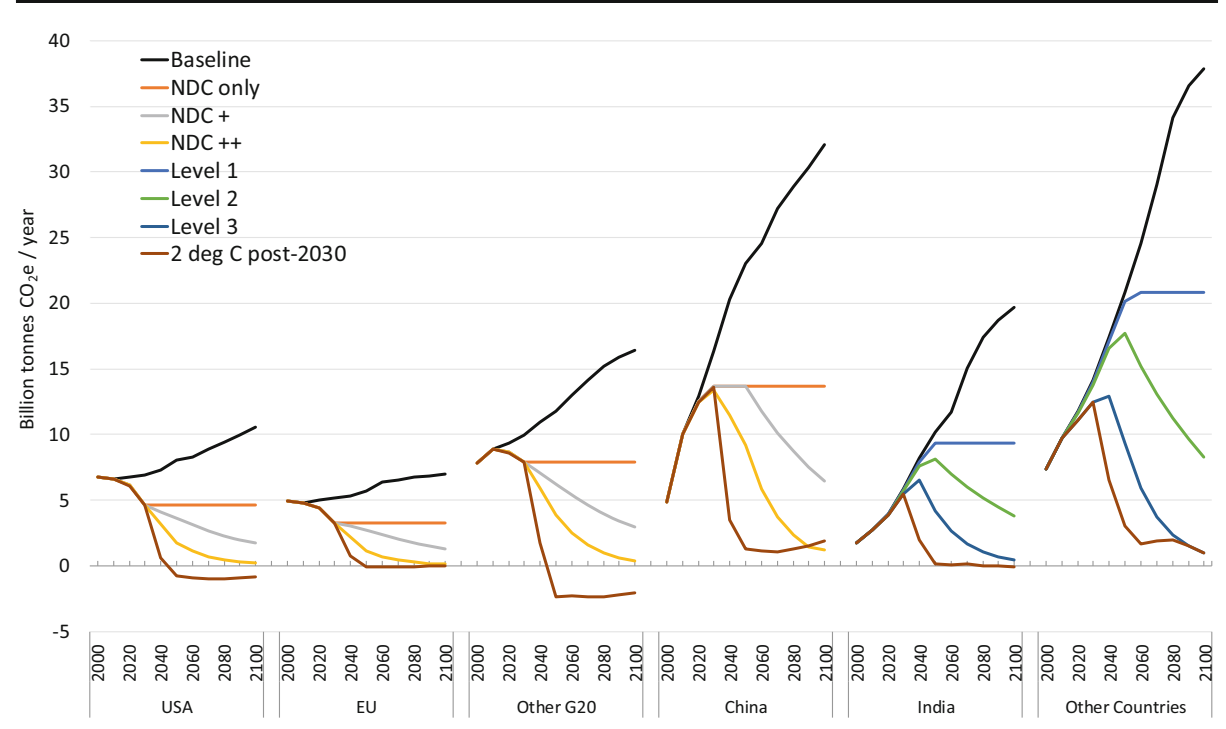

Fig. 1 Regional greenhouse gas emissions under each policy. Baseline results are from scenario 1. India and Other Countries baseline emissions shift slightly ( 1\% by 2100$)$ across scenarios $1-4$ due to market feedbacks. For all regions, results for policy scenarios are similar regardless of policies in other regions. Regions are not choosing to pay to relax emissions caps for these scenarios except for a small amount in China in 2100 in scenario 7. See SM for discussion of relaxation of caps, especially when CCS is unavailable

Scenario 8 defines a post-2030 global emissions pathway with a good chance of meeting the Paris goal. Comparing scenario 8 to scenario 7 , we can gain insights into the required stringency for regional emission reductions. We find that scenario 7 , our most ambitious regional policy scenario, is likely inadequate with respect to the $2{ }^{\circ} \mathrm{C}$ target. Temperature is discussed in the next section. Emissions need to decline even more precipitously immediately after 2030 in all regions (Fig. 1) if we are to place
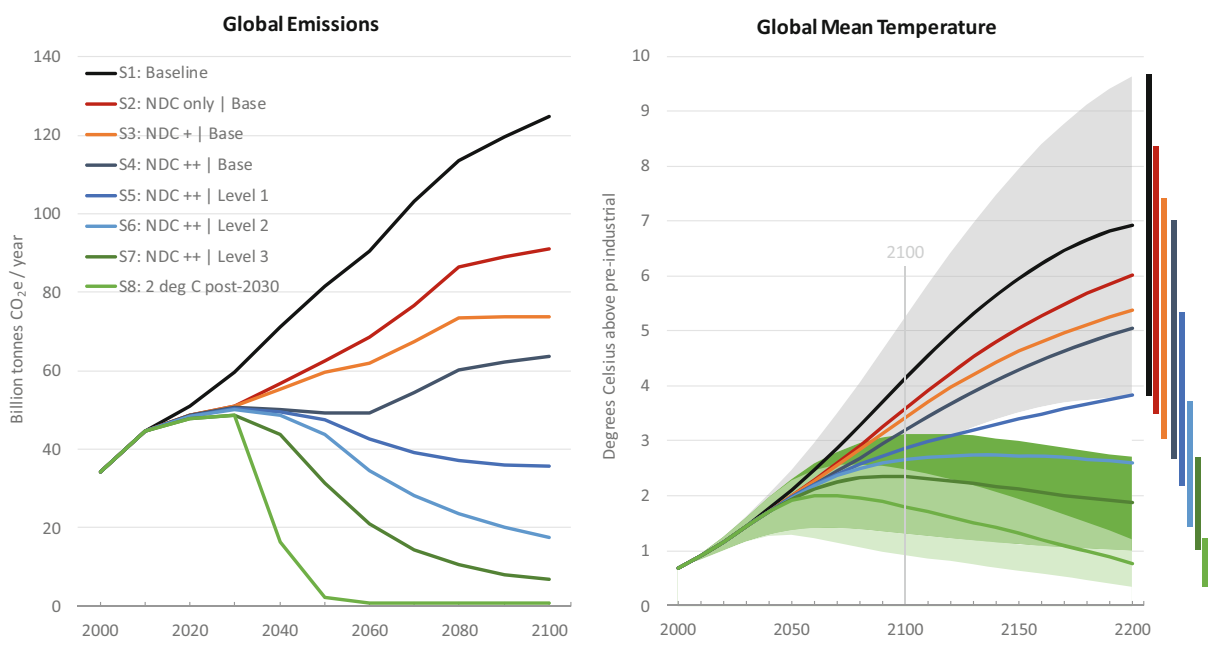

Fig. 2 Global emissions (a) and global mean temperatures (b) for various long-run policy scenarios. Lines reflect projected warming with ECS of $3{ }^{\circ} \mathrm{C}$. Shaded areas and 2200 ranges reflect warming with ECS uncertainty 1.5 to $4.5^{\circ} \mathrm{C}$. Shaded areas only shown for scenarios 1,7 , and 8 
the world on an emissions path with a high likelihood of staying below $2{ }^{\circ} \mathrm{C}$. As we observe later, this has profound implications for the energy infrastructure of and the costs borne by regional economies.

\section{The impact on global mean temperature}

Next, we examine the implications of the scenarios for long-run global mean temperature over the next two centuries. In general, our results provide a mapping between combinations of potential regional effort and temperature outcomes. See Figure SM2 for emissions and temperature results for additional combinations.

In Fig. 2b, solid lines indicate the temperature change resulting from each policy scenario's global emissions pathway assuming an equilibrium climate sensitivity (ECS) of $3{ }^{\circ} \mathrm{C}$. The vertical bars to the right show climate system response uncertainty by 2200 for a $67 \%$ confidence interval, produced by varying ECS between 1.5 and $4.5{ }^{\circ} \mathrm{C} .{ }^{10}$ We also, with shading, portray the $67 \%$ confidence intervals over the entire time horizon for the baseline and the lowest warming scenarios. In the baseline case of no additional measures to constrain emissions (scenario 1), global mean surface temperature could rise by approximately $7.0^{\circ} \mathrm{C}$ by 2200 assuming the central ECS, with a $67 \%$ confidence interval of 3.8 to $9.6^{\circ} \mathrm{C}$. In the SM, we provide a summary of the global mean temperature confidence intervals for all scenarios for the years 2100 and 2200 (Table SM4).

From scenario 2 through to scenario 7 , we see the temperature implications of different combinations of regional effort, as well as the implications of successively tightening the global emissions constraint. In scenarios 2-4, the focus is exclusively on the major emitters. Scenario 2 shows the impact on global mean temperature if the major emitters were to implement their NDCs, but take no additional actions. With a central ECS, the temperature reduction from baseline is $0.9{ }^{\circ} \mathrm{C}$ in 2200 . This contrasts with scenarios 3 and 4 where the four regions implement more ambitious long-term policies for controlling emissions, producing reductions of 1.5 and $1.9{ }^{\circ} \mathrm{C}$, respectively, in 2200. Note that, while an ambitious commitment on behalf of the current group of major emitters (scenario 4) can achieve a substantial reduction from baseline temperatures, it is insufficient to avoid continued warming.

It is not until we include constraints on virtually all countries that our results begin to approach the limits on temperature increase suggested in the Paris Agreement (scenarios 5, 6 , and 7). In the case of scenario 5, global mean temperature increase in 2200 with the central ECS is reduced to $3.8^{\circ} \mathrm{C}$, and for scenario 6 , to $2.6^{\circ} \mathrm{C}$. The earlier and additional reductions by India and $\mathrm{OC}$ in scenario 6 have a distinct effect, resulting in a peaking of temperature. However, the scenario has a central tendency rising and staying above $2{ }^{\circ} \mathrm{C}$ and only a very modest likelihood of staying below that threshold, which would only be realized if the climate system is less sensitive.

Among our bottom-up scenarios, it is only in our most ambitious scenario 7 that we achieve a $2{ }^{\circ} \mathrm{C}$ target in the year 2200 (with a central ECS). Notice though that we approach it from

\footnotetext{
${ }^{10}$ ECS is a measure of the long-term response of global mean temperature to a fixed radiative forcing, typically an instantaneous doubling of $\mathrm{CO}_{2}$ concentrations from preindustrial levels. Three degrees Celsius is the Meehl et al. (2007) ECS mode. Bindoff et al. (2013) did not identify a central value. 1.5 to $4.5^{\circ} \mathrm{C}$ is characterized by Bindoff et al. (2013) as the ECS range that is 66-100\% likely to occur. In our modeling, we ensure consistency with observations by jointly varying ECS, temperature lag, and radiative forcing from aerosols.
} 
above, that is, after overshooting $2{ }^{\circ} \mathrm{C}$. More importantly, however, the scenario has shifted the distribution such that a fraction of the $67 \%$ confidence interval stays below $2{ }^{\circ} \mathrm{C}$ throughout the time horizon.

The reality of the challenge is clear. Emissions reductions among the current group of major emitters can make a significant contribution to reign in the increase in temperature but it will require substantial individual country effort post-2030 in both developed and developing countries at least equal to that specified in our scenario 7 to even have a chance of temperatures consistent with the aspirations of the Paris Agreement.

This conclusion is underscored by scenario 8 . This post-2030 pathway, with a much better chance of limiting warming to $2{ }^{\circ} \mathrm{C}$, requires that global emissions decline to zero by 2060 . Due to the dynamics of the climate system, economies will need to avoid GHG-emitting capital to insure that GHG concentrations in the atmosphere decline along with global mean surface temperature. ${ }^{11}$

While avoiding $2{ }^{\circ} \mathrm{C}$ of warming may be difficult, it is important to recognize that further effort has two effects - in addition to lowering the central tendency (the solid line), it is also shifting and compacting the distribution of potential temperature outcomes for a given emissions pathway. In particular, the additional effort is reducing the risk of higher levels of warming. For example, the $67 \%$ confidence interval shifts from a baseline warming range in 2200 of 3.8-9.6 to $3.5-8.3{ }^{\circ} \mathrm{C}$ with NDC only effort by the major emitters (scenario 2 ) and to $1.0-2.7^{\circ} \mathrm{C}$ with NDC++ and level 3 effort (scenario 7). Thus, emissions reduction effort of any kind reduces the risk of global warming.

\section{The energy sector}

It is important to distinguish between two issues: the impact of a particular set of regional emissions constraints on temperature and the challenge of meeting those constraints. As we saw above, ambitious post-2030 emissions reduction policies in developed and developing countries will be required for even a chance at limiting warming to below $2{ }^{\circ} \mathrm{C}$ (Fig. 1). However, we also saw that even the least ambitious regional policies analyzed are non-trivial by mid-century, with the level of effort particularly significant for transitional and developing economies.

The challenge of regional emissions reductions is both technological and economic, with many factors whose evolution over time is uncertain, such as the costs, timing, and emission characteristics of the available technologies and, indeed, what technologies will be available at all. ${ }^{12}$ Sizing up the challenge requires taking a careful look at the regional energy system transformations implied. Physical details of potential future energy infrastructure consistent with emissions constraints provide a tangible characterization of the scale of the challenges for regions, informing strategic thinking about investments, operations, and research and development, as well as the overall policy objectives - the levels of regional and global ambition.

By 2050, regional electricity and energy systems will need to be vastly differently from those in place today, even in the less ambitious scenarios (Fig. 3). Figure 3 shows the

\footnotetext{
${ }^{11}$ Scenario 8 temperatures continue to decline to 2200 due to negative annual global $\mathrm{CO}_{2}$ emissions from 2050 to 2200 (Figure SM4). The same is true for scenario 7 with negative $\mathrm{CO}_{2}$ emissions from 2090.

${ }^{12}$ See SM Section 1c for a discussion of energy sources and technology assumptions. For this analysis, we aggregate into broad categories for presentation purposes.
} 
regional electricity generation mix in 2010 and 2050, as well as electricity's share of total final energy consumption. In general, our results indicate growth in electricity demand, particularly in emerging and developing countries, and the deployment of new technology portfolios. The rate of regional energy system transformation depends on the policy ambition; however, even the less ambitious scenarios include rapid deployment of low-, zero-, or even negative-carbon electricity supply. At the same time, freely emitting fossil generation decreases with policy ambition, though it could grow relative to today in developing regions with more moderate emissions constraints. Meanwhile, regional fossil generation in total-without and with $\mathrm{CO}_{2}$ capture - could increase. An exception is the $2{ }^{\circ} \mathrm{C}$ post-2030 pathway, where even the residual $\mathrm{CO}_{2}$ emissions associated with fossil carbon capture technologies need to be avoided by $2050 .{ }^{13}$ In scenario 8 , regions need to transition away from fossil generation of any kind, which also illustrates the importance of expectations about future policies (discussed below).

Growth in electricity demand is driven not only by growing populations and economic development but also by electricity's changing role in a low-carbon economy, with a rising share in final energy in all regions and scenarios over time. ${ }^{14}$ Depending on regional policy design and the decarbonization options available both inside and outside the electric sector, end-use substitution away from fossil fuels towards low-carbon electricity, and greater reliance on that electricity as overall energy consumption declines, could be a costeffective strategy to decarbonize the economy (Figure SM5). This sort of future implies an increased dependence on regional electric systems and raises energy system integration issues.

Technology availability and costs will also affect the investment and generation mix, as well as the potential feasibility of climate goals. Given uncertainty about technology, a different generation mix may be cost-effective by 2050. For instance, the availability of CCS could significantly affect the size and composition of cost-effective regional power systems (Figures SM6 and SM7). Without CCS for fossil- or biomass-based generation, regions will need to comply with their emissions constraints by deploying a low-carbon generation mix with more nuclear, bioenergy without capture, and non-bioenergy renewables, as well as with smaller power and energy systems. Without a key advanced low-carbon technology, such as CCS, we find increased reliance on price-induced demand reductions and efficiency improvements economy-wide. Furthermore, without a negative emissions technology, such as biopower with CCS, we may not be able to produce a post-2030 global emissions pathway that stays below $2{ }^{\circ} \mathrm{C}$. Our results suggest that a negative emissions technology may be essential to meet such a temperature target if we do little more than the NDCs to constrain emissions by 2030.

Expectations about future policy can also influence today's energy investments and operations, even decades before the policy. For instance, in the Other Countries' region, we find that the timing and aggressiveness of the regional emissions peak-and-decline policy affect investments and retirements 20 years earlier. Specifically, an earlier and more

\footnotetext{
${ }^{13}$ Capture technologies can capture at most $90 \%$ of $\mathrm{CO}_{2}$. Note that, between 2030 and 2050, fossil energy technologies could still play a role.

${ }^{14}$ Note that electricity's share in final energy does not rise at the same rate in all regions. For example, the increase in India is comparatively low. This result is due to a large increase in the share of final energy used for passenger vehicles (currently low in India), which under our baseline assumptions for developing countries remains primarily fueled by non-electric energy. The evolution of the structure of baseline energy demand is significantly uncertain, particularly in developing countries.
} 


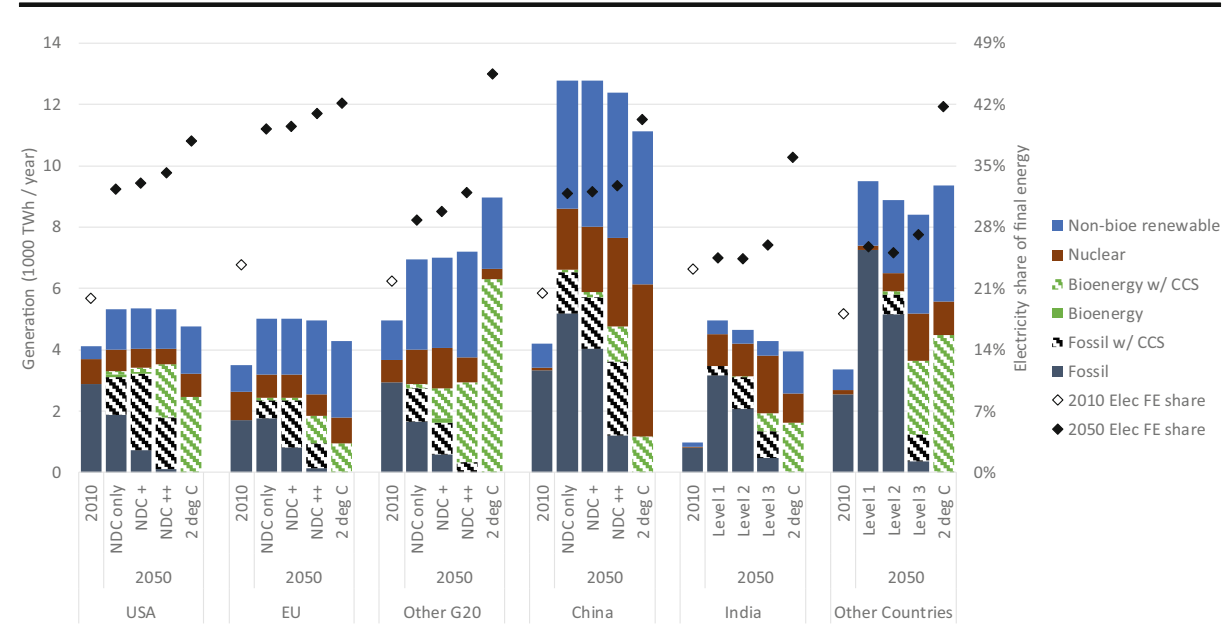

Fig. 3 Regional 2010 and 2050 electricity generation and electricity final energy share by level of emissions reduction ambition. For USA, EU, Other G20, and China, results from scenarios 2-4 and 8 shown. For India and Other Countries, results from scenarios 5-7 and 8 shown. Results vary slightly with the policy ambition of others due to market feedbacks

aggressive peak-and-decline policy (Level 3 vs. Level 1) motivates increased use of gas versus coal generation and the accelerated deployment of renewables in 2020 and 2030, decades prior to the introduction of the policy (Figure SM8), resulting in a significantly different generation portfolio by 2040 . Overall, investors will be confronted by uncertainty about future policy ambition and timing, and their expectations and corresponding investment decisions will depend on the credibility of proposed policy goals and emissions paths.

Finally, we observe that there may be constraints on what regions can accomplish alone in terms of emissions reductions within their borders. We find that with very tight emissions constraints, some regions choose to spend $\$ 1000 / \mathrm{tCO}_{2} \mathrm{e}$ to relax their emissions caps towards the end of the century, in particular without CCS available (see SM $1 \mathrm{f}$ and 2 for results and discussion). While the timing and magnitude of this safety valve use will vary with assumptions, the result conceptually illustrates that emissions reductions within countries may be bounded - technologically or economically (in terms of what countries are willing to pay). As such, additional reductions may only be possible through some form of international cooperation (e.g., emissions trading, financial or technological transfers, offsets) or improved availability of advanced technologies.

\section{Welfare costs of abatement}

The potential economic implications of abatement policies are crucial to consider (distinct from the valuation of avoided climate impacts). MERGE provides an explicit account of the cost of climate policy on regional consumption, a common basis for social welfare metrics. In each scenario, we compute the annual regional costs of emissions constraints measured as reductions in regional per capita consumption from baseline levels and integrate the costs across time to produce aggregate discounted measures of regional consumption losses (Table 2). Table 2, therefore, quantifies the potential cost of avoiding 
emissions. We stress, however, that we do not examine the potential benefits in terms of damages avoided. ${ }^{15}$

Table 2 provides regional discounted consumption costs for the policies by level of effort. Intuitively, within each region, costs increase with policy ambition, but the increases vary by region due to differences in relative effort and technology options. For example, we find costs doubling (USA, EU), tripling (China), quadrupling (OG20), or more (India, OC) as regions move from the least to most ambitious regional policies and are forced towards increasingly more expensive energy solutions (section 5). The differences in costs across regions are also significant with, for instance, notably higher costs in China in both level terms and as a fraction of the regional economy compared to the USA, EU, and other G20. ${ }^{16,17}$

The $2{ }^{\circ} \mathrm{C}$ post-2030 emissions pathway is particularly demanding in every region, resulting in substantial cost increases compared to the most ambitious regional policies of scenario 7 . The very sharp reduction in emissions post-2030 for the $2{ }^{\circ} \mathrm{C}$ pathway is costly as it (a) forces early retirement of capital with a rapid transition away from today's fossil generation, (b) precludes future use of fossil fuels even with $\mathrm{CO}_{2}$ capture, and (c) requires large expansion of zero- and negative-emitting generation by mid-century.

Like policy ambition, technology availability and costs are key determinants of the regional cost implications. For instance, pursuing the more ambitious policies without CCS will be more expensive, with some regions affected significantly more than others (e.g., a 60\% increase in US costs in scenario 7) and very low temperature goals potentially unattainable (Tables SM6 and SM7). ${ }^{18}$

When comparing scenarios, we also want to take into account the overall magnitude of global costs and the distribution of costs across regions. There are alternative approaches to aggregating regional effects based on alternative social welfare theoretic perspectives. These differ in terms of how they address regional differences in per capita consumption losses over time. If we report global welfare changes as a sum of changes in aggregate consumption across regions, we are adopting a "utilitarian" perspective. However, it is also possible to adopt a perspective based on a different social welfare metric that gives more weight to consumption losses in poorer regions. We refer to this welfare metric as "inequality averse," and present results with different degrees of aversion, where a smaller parameter value represents greater weighting of the effects on poorer regions where the marginal value of a dollar is higher. (See SM Section 1e for additional discussion and an exposition of these ideas.)

Table 2 presents global costs from utilitarian and inequality averse perspectives. In all cases, the impacts have been converted to a money-metric percentage loss in global welfare. With greater inequality aversion (lower sigma), the consumption

\footnotetext{
${ }^{15}$ Our framework also does not consider potential climate feedbacks nor growth effects either from mitigation costs or climate impacts which, among other things, could affect our baseline. These types of feedbacks are currently not well understood.

${ }^{16}$ Care is warranted when interpreting regional cost differences. A major explanatory factor is the absolute energy intensity of regional GDP, which is subject to measurement error due to model calibration based on market exchange rates, a standard calibration practice.

${ }^{17}$ Note that Table 2 illustrates that countries could experience spillover effects and potential benefits. For instance, countries without climate policy or with more moderate policy could benefit from lower global fossil fuel prices (e.g., India and Other Countries in scenarios 2-4).

18 This result confirms the importance of CCS, and negative emissions technologies in particular, to very low temperature goals (e.g., Riahi et al. 2015; Clarke et al. 2014).
} 


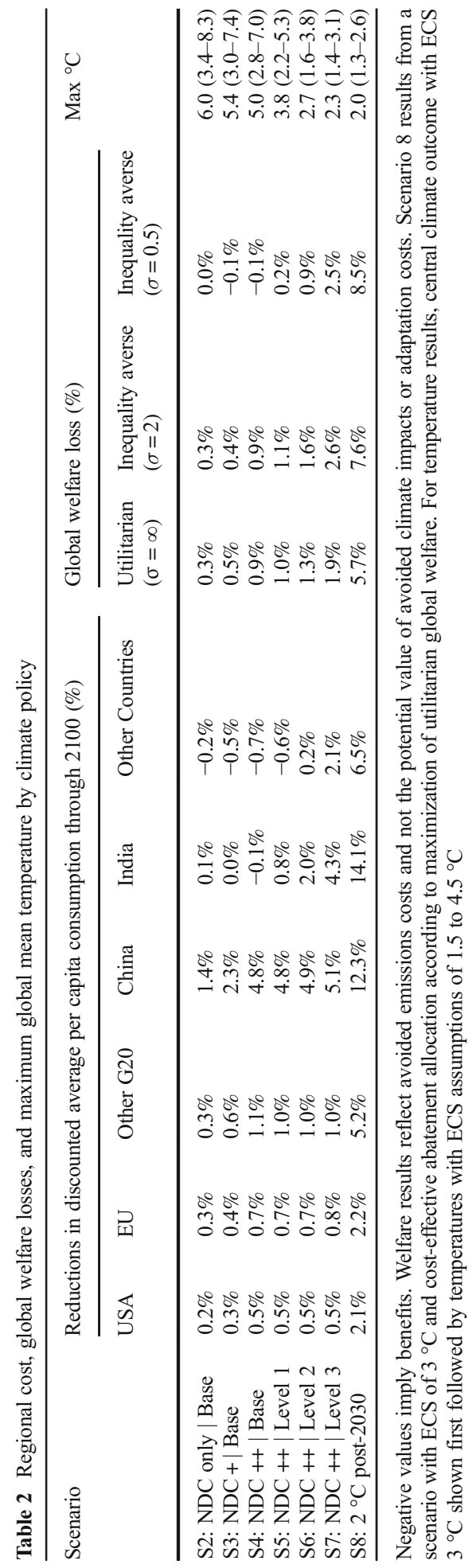


effects in India and Other Countries are of increased importance. In scenarios with no policy or lower ambition in these regions, there are consumption gains or relatively small losses, and the stronger inequality aversion metric suggests lower global welfare losses than the utilitarian perspective. However, the opposite occurs under the most ambitious scenarios (scenarios 7 and 8), where the consumption losses from very tight regional emissions constraints in India and Other Countries are weighted more heavily with inequality aversion and suggest larger global welfare losses. ${ }^{19}$ Most importantly, we find that regardless of one's welfare perspective, we can draw two robust conclusions: global welfare losses increase with ambition and losses increase substantially for the $2{ }^{\circ} \mathrm{C}$ post-2030 pathway.

Finally, comparing global welfare costs to the maximum temperature realized over time in each scenario (last four columns of Table 2), we observe a non-linearity in costs with incremental reductions in maximum warming increasingly more costly for society. For instance, moving from scenario 6 to 7 , lowers the maximum temperature $0.4{ }^{\circ} \mathrm{C}$ at an additional cost to global welfare of $0.6-1.6$ percentage points across welfare perspectives ( $\$ 10$ trillion in discounted aggregate global consumption), while avoiding another $0.3{ }^{\circ} \mathrm{C}$ moving from scenario 7 to 8 comes at a much steeper incremental cost to welfare of 3.8-6.0 percentage points (over $\$ 60$ trillion). Costs are therefore rising quickly as we further constrain warming, and society will need to consider the value of additional avoided warming and the trade-offs with other societal priorities.

\section{Concluding comments}

NDCs are the new metric in measuring a country's commitment to dealing with the threat of climate change. The Paris Agreement represents an important first step in a process that will involve repeated negotiations. Each round of NDCs should be evaluated in terms of its contribution to the overall global goals. This paper examines the impacts of a wide range of potential future regional commitments on GHG emissions and global mean temperature and explores regional emissions pathways, technology transformations, and welfare costs associated with realizing alternative lower greenhouse gas-emitting futures. We do not speculate about the likelihood of the different regional emissions pathways, focusing instead on the potential outcomes from a range of scenarios.

Action on climate change will depend on domestic policies and investments. It is critical to evaluate the tangible implications of such efforts. Even though the initial round of NDCs represents a consequential first step, it is only a first step if we are to meet the long-run goal of containing temperature increase to well below $2{ }^{\circ} \mathrm{C}$. Future climate will be determined by combinations of country-level ambition where additional effort, even modest effort, can reduce climate change risks. However, the objective of the Paris Agreement represents an enormous challenge for all regions, requiring significantly constrained emissions beyond 2030 in developed, transitional, and developing countries and massive transformation of regional electric sectors and energy systems. The global distribution of welfare costs will also matter as will the non-linearity in costs as regions pursue increasingly more ambitious emissions constraints and potentially confront limits

\footnotetext{
${ }^{19}$ Note that regional abatement may not be financed domestically. International financial transfers could shift the welfare implications across regions.
} 
domestically. Political challenges and technological uncertainty will be factors, and consideration of the value of long-run objectives and trade-offs will be an ongoing process based on the availability of new information.

The hallmark of industrialization in the twentieth century was its reliance on inexpensive and abundant fossil fuels, the by-products of which have increased atmospheric greenhouse gas concentrations significantly. The challenge for the twenty-first century will be to ensure that the foundation of the development process for today's low-income countries rests upon alternative low-GHG sources of energy. Otherwise, any headway made by current major emitters to put global emissions on a downward track will be overwhelmed as growth in the developing world releases GHGs into the atmosphere at what may turn out to be a perilous rate.

The path forward will be defined by technological development, policy implementation, and expectations, shaping the role of sectors, regions, and technologies, and determining costs and environmental effectiveness. In addition to research and development strategies, countries should evaluate actions that could provide flexibility and welfare benefits, such as economywide approaches, harmonized emission taxes, and trading markets that cross national boundaries. ${ }^{20}$ Flexibility will be critical given the magnitude of the challenge. For this analysis, we have allowed regions to choose how best to meet emissions constraints. Policies with sectoral requirements for renewables, emissions caps, and/or efficiency would have different technology and cost implications, with costs that are greater than or equal to those shown in this paper. It is unclear, however, how negative emissions caps would be implemented.

There are also, of course, other measures for dealing with the threat of climate change in addition to slowing emissions growth. Adaptation is already proving crucial for responding effectively to changing conditions. Geoengineering, or large-scale intervention in the Earth's climatic system, is another and more controversial measure. Although the subject of fierce debate, many would agree that geoengineering is worthy of greater enquiry. ${ }^{21}$ Ultimately, managing the risks of climate change will not be a choice between abatement, adaptation, accelerated $\mathrm{R} \& \mathrm{D}$, or even geoengineering, but a mixture of strategies, the emphasis of which is likely to change over time.

Finally, the present analysis does not consider the issue of economic efficiency. To do so would require characterizing an emission reduction strategy that minimizes the expected sum of abatement costs and the damages linked to climate change. Our analysis provides only a perspective on abatement costs. A better understanding of the potential damages, including the magnitude and potential likelihood of catastrophes, would be required to conduct such a cost-benefit examination. This sort of analysis is beyond the scope of the present study. In this context, uncertainty need not (and should not) lead to "policy paralysis." When it comes to dealing with the threat of climate change, the level and mix of actions should depend upon our best understanding of the stakes, the odds, and society's attitude towards risk. As we learn, we must be prepared to make midcourse corrections and adjust our response accordingly.

Open Access This article is distributed under the terms of the Creative Commons Attribution 4.0 International License (http://creativecommons.org/licenses/by/4.0/), which permits unrestricted use, distribution, and

${ }^{20}$ See Stavins et al. (2014) for a discussion of policies and instruments.

${ }^{21}$ For example, see Keith (2013). 
reproduction in any medium, provided you give appropriate credit to the original author(s) and the source, provide a link to the Creative Commons license, and indicate if changes were made.

\section{References}

Bindoff, NL et al (2013) Detection and attribution of climate change: from global to regional. In: climate change 2013: the physical science basis. Intergovernmental panel on climate change. Cambridge University Press, Cambridge, UK and New York, NY, USA

Clarke L et al (2014) Assessing transformation pathways. In: Climate change 2014: mitigation of climate change. Intergovernmental panel on climate change. Cambridge University Press, Cambridge, UK and New York, NY, USA

COP21 (2015) The paris agreement, United Nations Framework Convention on Climate Change, Paris France, December 2015

Fawcett A et al (2015) Can Paris pledges avert severe climate change? Science 350(6265):1168-1169

Iyer GC et al (2015) The contribution of Paris to limit global warming to $2^{\circ} \mathrm{C}$. Environ Res Lett 10

Jacoby HD, Y-H Chen (2014) Expectations for a new climate agreement. MIT Joint Program on the Science and Policy of Global Change, Report 264, August

Keith D (2013) A case for climate engineering. Boston review books. MIT Press, Boston, p 112

Kriegler E et al (2015) Making or breaking climate targets: the AMPERE study on staged accession scenarios for climate policy. Technol Forecast Soc Chang 90(Part A):24-44

Meehl GA et al (2007) Global climate projections. In: Climate change 2007: the physical science basis. Intergovernmental panel on climate change. Cambridge University Press, Cambridge, UK and New York, NY, USA.

Pizer WA (1997) Prices vs quantities revisited: the case of climate change. Discussion paper 98-02, resources for the future, Washington DC

Reilly J et al (2015) Energy \& climate outlook: perspectives from 2015. MIT Joint Program on the Science and Policy of Global Change

Riahi K et al (2015) Locked into Copenhagen pledges - implications of short-term emission targets for the cost and feasibility of long-term climate goals. Technol Forecast Soc Chang 90:8-23

Rogelj J et al (2016) Paris agreement climate proposals need a boost to keep warming well below $2^{\circ} \mathrm{C}$. Nature 234:631-639

Stavins R et al (2014) International cooperation: agreements and instruments. In: Climate change 2014: mitigation of climate change. Intergovernmental panel on climate change. Cambridge University Press, Cambridge, UK and New York, NY, USA

UNEP (2015) The emissions gap report 2015. United Nations Environment Programme, November 2015

UNFCCC (1994) United Nations framework convention on climate change, March 21, 1994. 